Sensitivity and specificity of US were calculated using microscopic findings as the gold standard.

Results: 101 patients have been enrolled in the study. 33 patients have been excluded due to loss of anatomical pieces at surgery. The mean age of the remaining 68 pts was 71 yo $( \pm 8), 44$ women, 34 were affected by CPPD according to microscopy. Overall and per site diagnostic US accuracy results are presented in table 1

\begin{tabular}{lccccc}
\hline & $\begin{array}{c}\text { Diagnostic } \\
\text { accuracy }\end{array}$ & Sensitivity & Specificity & $\begin{array}{c}\text { Positive } \\
\text { Predictive } \\
\text { value }\end{array}$ & $\begin{array}{c}\text { Negative } \\
\text { Predictive } \\
\text { value }\end{array}$ \\
\hline Global & 0.75 & 0.91 & 0.59 & 0.69 & 0.87 \\
Medial meniscus & 0.82 & 0.87 & 0.77 & 0.77 & 0.87 \\
Lateral meniscus & 0.75 & 0.83 & 0.68 & 0.68 & 0.83 \\
Medial cartilage & 0.86 & 0.79 & 0.92 & 0.88 & 0.85 \\
$\begin{array}{l}\text { Lateral cartilage } \\
\text { Medial side (com- }\end{array}$ & 0.82 & 0.71 & 0.88 & 0.77 & 0.84 \\
$\quad$ bined cartilage and & 0.82 & 0.88 & 0.76 & 0.79 & 0.87 \\
$\quad$ meniscus) & & & & & \\
$\begin{array}{l}\text { Lateral side (com- } \\
\text { bined cartilage and }\end{array}$ & 0.78 & 0.88 & 0.69 & 0.73 & 0.86 \\
meniscus) & & & & & \\
\end{tabular}

Conclusion: Our results demonstrate that US is an accurate exam for identification of CPPD. The best combination of sensitivity and specificity is achieved by examining the medial aspect of the knee.

References:

[1] Filippou G, Scirè CA, Adinolfi A, et al. Identification of calcium pyrophosphate deposition disease (CPPD) by ultrasound: reliability of the OMERACT definitions in an extended set of joints-an international multiobserver study by the OMERACT Calcium Pyrophosphate Deposition Disease Ultrasound Subtask Force. Ann Rheum Dis 2018;:annrheumdis-2017-212542. doi:10.1136/annrheumdis-2017-212542

Disclosure of Interests: Georgios Filippou: None declared, Anna Scanu: None declared, Antonella Adinolfi: None declared, Carmela Toscano: None declared, Dario Gambera: None declared, Raquel Largo: None declared, Esperanza Naredo: None declared, Emilio Calvo: None declared, Gabriel Herrero-Beaumont: None declared, Pascal Zufferey: None declared, Christel Madelaine-Bonjour: None declared, Daryl MacCarter: None declared, Stanley Makman: None declared, Zachary Weber: None declared, Fabiana Figus: None declared, Ingrid Möller: None declared, Marwin Gutierrez: None declared, Carlos Pineda: None declared, Denise Clavijo Cornejo: None declared, Héctor García: None declared, Victor Ilizaliturri: None declared, Jaime Mendoza Torres: None declared, Raul Pichardo: None declared, Luis Carlos Rodriguez Delgado: None declared, Emilio Filippucci Speakers bureau: Dr. Filippucci reports personal fees from AbbVie, personal fees from Bristol-Myers Squibb, personal fees from Celgene, personal fees from Roche, personal fees from Union Chimique Belge Pharma, personal fees from Pfizer, outside the submitted work., Edoardo Cipolletta: None declared, Teodora Serban: None declared, Catalin Cirstoiu: None declared, Florentin Ananu Vreju: None declared, Dun Grecu: None declared, Gael Mouterde: None declared, Marcello Govoni: None declared, Leonardo Punzi: None declared, Nemanja Damjanov Grant/research support from: from AbbVie, Pfizer, and Roche, Consultant of: AbbVie, Gedeon Richter, Merck, Novartis, Pfizer, and Roche, Speakers bureau: AbbVie, Gedeon Richter, Merck, Novartis, Pfizer, and Roche, Lene Terslev Speakers bureau: LT declares speakers fees from Roche, MSD, BMS, Pfizer, AbbVie, Novartis, and Janssen., Carlo Alberto Scirè: None declared, Annamaria lagnocco Grant/research support from: Abbvie, MSD and Alfasigma, Consultant of: AbbVie, Abiogen, Alfasigma, Biogen, BMS, Celgene, Eli-Lilly, Janssen, MSD, Novartis, Sanofi and Sanofi Genzyme, Speakers bureau: AbbVie, Alfasigma, BMS, Eli-Lilly, Janssen, MSD, Novartis, Sanofi DOI: 10.1136/annrheumdis-2020-eular.3812

\section{OP0318 \\ THE ROLE OF DUAL ENERGY COMPUTED TOMOGRAPHY (DECT) IN THE DIFFERENTIATION OF GOUT AND CALCIUM PYROPHOSPHATE DEPOSITION DISEASE}

D. Kravchenko ${ }^{1}$, P. Karakostas ${ }^{2}$, P. Brossart ${ }^{2}$, C. Behning ${ }^{3}$, C. Meyer ${ }^{1}$, V. S. Schäfer ${ }^{2} .{ }^{1}$ University Hospital Bonn, Department of Interventional and Diagnostic Radiology, Bonn, Germany; ${ }^{2}$ University Hospital Bonn, Clinic for Internal Medicine III, Department of Oncology, Hematology and Rheumatology, Bonn, Germany; ${ }^{3}$ University Hospital Bonn, Institute for Medical Biometrics, Informatics and Epidemiology (IMBIE), Bonn, Germany

Background: Differentiation of gout and calcium pyrophosphate deposition disease (CPPD) is sometimes difficult as patients often present with a similar clinical picture. Arthrocentesis and subsequent polarization microscopy (PM) remains the gold standard but novel diagnostic approaches such as non-invasive dual energy computed tomography (DECT) have recently been validated for gout. Currently, limited data is available on DECT in patients with CPPD.

Objectives: To analyse the diagnostic impact of DECT in gout and CPPD when compared to the gold standard of PM. We further compared the results of PM to ultrasound (US), conventional radiographs (CR), and suspected clinical diagnosis (SCD). Additionally, 15 laboratory parameters were analysed.

Methods: Twenty-six patients diagnosed with gout $(n=18)$ or CPPD $(n=8)$ who received a DECT and underwent arthrocentesis were included. Two independent readers assessed colour coded, as well as 80 and $120 \mathrm{kV}$ DECT images for signs of monosodium urate (MSU) crystals or CPP deposition. US and CR from the patient's initial visit along with the SCD were also compared to PM. US examinations were performed by certified musculoskeletal ultrasound specialists. The association of up to 15 laboratory parameters such as uric acid, thyroid stimulating hormone, and C-reactive protein (CRP) with the PM results was analysed. Results: Sensitivity of DECT for gout was $67 \%(95 \% \mathrm{CI} 0.41-0.87)$ with a specificity of $88 \%(95 \% \mathrm{Cl} 0.47-1.0)$. Concerning CPPD, the sensitivity and specificity of DECT was $63 \%(95 \% \mathrm{Cl} 0.25-0.91)$ and $83 \%(95 \% \mathrm{Cl} 0.59-0.96)$ respectively. US had the highest sensitivity of $89 \%(95 \% \mathrm{Cl} 0.65-0.99)$ with a specificity of $75 \%(95 \% \mathrm{Cl} 0.35-0.97)$ for gout, while the sensitivity and specificity for CPPD were $88 \%(95 \% \mathrm{Cl} 0.47-1.0)$ and $89 \%(95 \% \mathrm{Cl} 0.65-0.99)$ respectively. The SCD had the second highest sensitivity for gout at $78 \%(95 \% \mathrm{Cl} 0.52-0.94)$ with a comparable sensitivity of $63 \%(95 \% \mathrm{Cl} 0.25-0.92)$ for CPPD. Uric acid levels were elevated in $33 \%$ of gout patients and $25 \%$ of CPPD patients. While elevated CRP levels were observed in $59 \%$ of gout patients and in $88 \%$ of CPPD patients, none of the 15 analysed laboratory parameters were found to be significantly linked.

Conclusion: DECT provides a non-invasive diagnostic tool for gout but might have a lower sensitivity than suggested by previous studies $\left(67 \%\right.$ vs $\left.90 \%{ }^{1}\right)$ DECT sensitivity for CPPD was $63 \%(95 \% \mathrm{Cl} 0.25-0.91)$ in a sample group of eight patients. Both US and the SCD had higher sensitivities than DECT for gou and CPPD. Further studies with larger patient cohorts are needed in order to determine the diagnostic utility of DECT in CPPD.

\section{References:}

[1] Bongartz, Tim; Glazebrook, Katrina N.; Kavros, Steven J.; Murthy, Naveen S.; Merry, Stephen P.; Franz, Walter B. et al. (2015): Dual-energy CT for the diagnosis of gout: an accuracy and diagnostic yield study. In Annals of the rheumatic diseases 74 (6), pp. 1072-1077. DOI: 10.1136/ annrheumdis-2013-205095.

Disclosure of Interests: None declared

DOI: 10.1136/annrheumdis-2020-eular.4571

\section{OP0319-PARE SEE ME HEAR ME: AN ANCA-ASSOCIATED VASCULITIS PATIENT CO-CREATION INITIATIVE}

S. Perera ${ }^{1}$, D. Krafcsik ${ }^{2}$, P. Rutherford ${ }^{2} .^{1}$ Digital Artist/Educator, Manchester, United Kingdom; ${ }^{2}$ Vifor Pharma, Medical Affairs, Zurich, Switzerland

Background: ANCA-associated Vasculitis (AAV) is a rare, severe small vessel vasculitis that affects multiple organs with a high acute mortality risk. As every patient presents differently, diagnosis is often delayed. Although treatments exist, responses vary, and remission is often not achieved or sustained. From the time of initial diagnosis onwards, patients suffer from an impaired quality of life. Coping with pain, fatigue, ongoing symptoms and combating challenges becomes a complex task and patients may be challenged in how best to communicate these emotions with health care professionals. We aimed to develop an initiative with Art and Voice, that would seek to empower people living with AAV and their carers in feeling understood, seen and heard in a meaningful way. This would invite a collective understanding of 'how people make sense of key life experiences and what it means to them' by creating a common language to address poorly addressed issues.

Objectives: This project aims to provide a voice to patients to express personal experiences and complexity of everyday living and empower people to feel in control of their own health through an online platform. It should also allow practitioners to gain new awareness about issues faced by their patients, to bette understand the relationships between caring and curing, hearing and listening. Methods: We collaborated with 10 patient association groups representatives, 17 AAV patients and 9 of their carers across 7 European countries. A series of workshops were set up to discuss issues faced and aid the subsequent production of a range of materials designed to provide clear, comprehensive content that would help individuals cope with the physical and emotional impact of AAV from diagnosis to living with it. This work was supported by a digital artist who is a rheumatologist living with vasculitis.

Results: The co-creation of patient information materials featuring real life patients was successful and led to the development of a creative initiative called SEE ME.HEAR ME with an online platform www.myancavasculitis.com. This includes: (1) an awareness programme featuring artwork created by the digital artist and advised by the patients which captures the essence of AAV from the patients view (see Figure). (2) a series of first-hand patient and carer stories capturing their authentic voice on 'what it is like to live with the disease'. (3) extensive 
Table 1. Sensitivities and specificities of examinations in gout and calcium pyrophosphate deposition disease

\begin{tabular}{lrrr}
\hline & DECT $\mathbf{n}=\mathbf{2 6}$ & US $\mathbf{n = 2 6}$ & $\begin{array}{c}\text { Conventional } \\
\text { Suspected clinical } \\
\text { Diagnosis } \mathbf{n = 2 6}\end{array}$ \\
\hline Gout & & & \\
Sensitivity & $66.67 \%(0.410-0.867)$ & $88.9 \%(0.652-0.986)$ & $61.5 \%(0.316-0.861)$ \\
Specificity & $87.5 \%(0.473-0.997)$ & $75 \%(0.349-0.968)$ & $100 \%(0.541-1.000)$ \\
CPPD & $62.5 \%(0.245-0.915)$ & $87.5 \%(0.523-0.936)$ \\
Sensitivity & $83.3 \%(0.586-0.964)$ & $88.9 \%(0.653-0.986)$ & $0 \%(0.000-0.459)$ \\
Specificity & & $62.5 \%(0.245-0.915)$ \\
\end{tabular}

${ }^{*} 95 \% \mathrm{Cl}$ in brackets

written content designed to fill information gaps around AAV diagnosis, investigations and treatment and what to expect during clinical follow up. The platform supports patients in asking questions and seeking information while signposting them to their own healthcare professional for advice and their local country patient association for support.

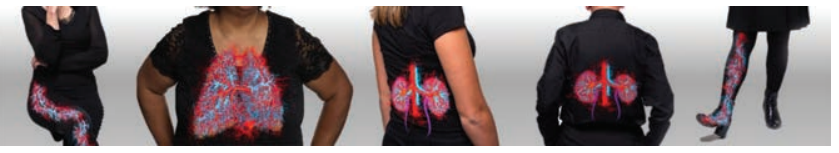

Conclusion: People with AAV need support throughout life, the profound psychosocial influence from illness makes the lived experience, challenging. SEE ME. HEAR ME online patient platform aims to generate awareness around AAV, improve physician and patient dialog, and enhance people's experiences of living and coping with the disease. In addition it provides support for carers and giving valuable insights to friends, family and the general public about what the lived experience with AAV looks like.

Acknowledgments: We wish to thank all European patients and patient association leads who worked on this project

Disclosure of Interests: Shanali Perera Consultant of: Vifor Pharma, Dijana krafcsik Employee of: Vifor Pharma, Peter Rutherford Shareholder of: Vifor Pharma, Employee of: Vifor Pharma, Baxter Healthcare DOI: 10.1136/annrheumdis-2020-eular.1494

\section{OP0320-PARE FIBROMYALGIA NETWORK - A MULTIDIMENSIONAL PROJECT FOR PEOPLE WITH FIBROMYALGIA SYNDROME}

A. Celano ${ }^{1}$, S. Mingolla ${ }^{2}$, I. Cinieri ${ }^{3}$, A. Marsico ${ }^{4} .{ }^{1} A P M A R R$, Lecce, Italy; ${ }^{1}$ APMARR, Lecce, Italy; ${ }^{3}$ Urbino University, Urbino, Italy; ${ }^{4}$ TA LHA, Taranto, Italy

Background: Fibromyalgia Syndrome (FMS) is a clinical non-joint syndrome characterized by diffuse, prolonged, and unexplained muscle pains. The health effects of FMS are pervasive and wide ranging. It is frequently associated with depression, anxiety and post-traumatic stress disorder. Patients describe living with daily unrelenting chronic widespread pain, persistent chronic fatigue, sleep issues, and cognitive effects. Fibromyalgia impacts all aspects of patients' lives. Patients report severe limitations in maintaining relationships, performing at work or school, and caring for self and family. They experience stigma within society, social isolation, healthcare and financial challenges of treatment, and fears of living with an often misunderstood condition. In 2019 APMARR launched Fibromyalgia Network a project that aimed at improving the quality of life of patients with FMS.

Objectives:

- Experiment a set of good practices at territorial level to be expanded nationally to improve the FMS patients' conditions

- Create a multisectoral, patient-oriented network with different stakeholders

- Launch a communication campaign to inform and change the perception of the pathology

- Train the General Practitioners in order to increase early diagnosis

- Empower the Patients

- Promote innovative treatments and the data acquisition about hyperbaric oxygen therapy

- Provide free psychological and information support

Methods: The project was based on the assumption supported by evidence that a multi-modal treatment approach improves the quality of life of person with FMS including a combination of drug and non-drug treatments and a range of health care specialties. All the activities implemented were shaped on a holistic approach to treating Fibromyalgia, including lifestyle management, diet and exercise, and psychosocial techniques, in addition to medical treatments.

Results:

1) A territorial network coordinated by APMARR was created involving Puglia Region, Health Authorities, Professional board of Psychologists, National
Association of People with FMS, Professional board of Physicians, Italian Society Of Rheumatology-Puglia

2) A communication campaign was widely spread among social network, a brochure was written in collaboration with the Italian Society of Rheumatology and distributed to the general public, a national level conference was organized in Bari

3) A training program acknowledged by the Italian Health Minister Program involved more than $120 \mathrm{GPs}$

4) A patients expert program involved more than 100 patients

5) A group of patients were tutored in their treatment with hyperbaric oxygen therapy and a report was sent to the HTA Italian Program in collaboration with the Puglia Region HTA Center. It was the first HTA report elaborated in collaboration with a patient organization in Italy

6) Self-mutual help groups were organized with free psychological support, as well as an information desk and a toll-free number

7) High satisfaction and pain relief of the participants as detected by a qualitative satisfaction questionnaire
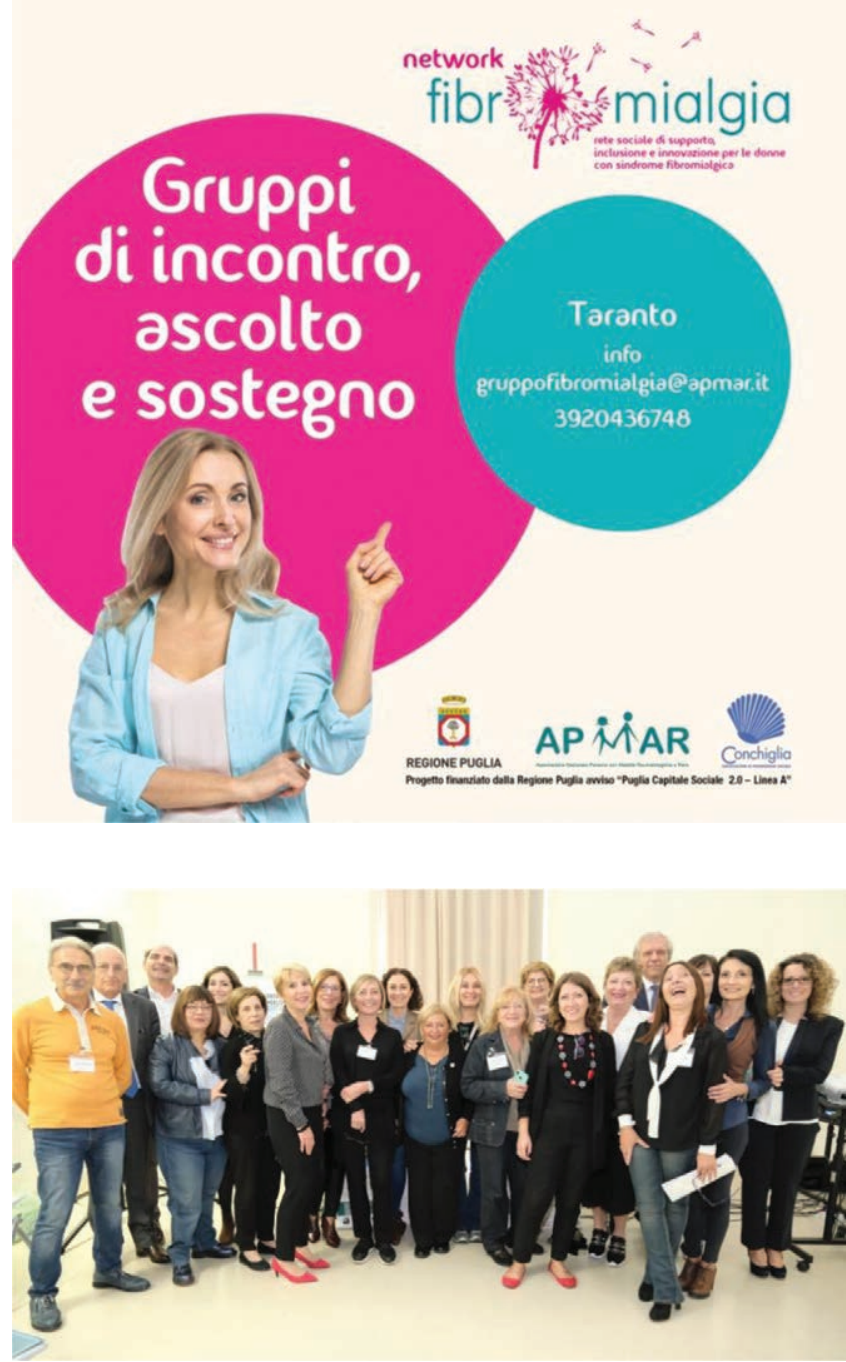

Conclusion: The project demonstrated the good results of the holis tic approach in the patients who took part in the program that reported the improvements of their quality of lives and relieve from their daily pains. The 